Check for updates

Cite this: Phys. Chem. Chem. Phys., 2020, 22, 13698

Received 17th February 2020, Accepted 4th June 2020

DOI: 10.1039/d0cp00897d

rsc.li/pccp

\section{Trends in stabilisation of Criegee intermediates from alkene ozonolysis $\dagger$}

\author{
Mike J. Newland, (D) *a Beth S. Nelson, (D) a Amalia Muñoz, (D) b Milagros Ródenas, \\ Teresa Vera, Joan Tárrega ${ }^{\mathrm{b}}$ and Andrew R. Rickard (D) ac
}

\begin{abstract}
Criegee Intermediates $(\mathrm{Cl})$, formed in the ozonolysis of alkenes, play a central role in tropospheric chemistry as an important source of radicals, with stabilised $\mathrm{Cl}(\mathrm{SCl})$ able to participate in bimolecular reactions, affecting climate through the formation of inorganic and organic aerosol. However, total $\mathrm{SCl}$ yields have only been determined for a few alkene systems, while speciated $\mathrm{SCl}$ yields from asymmetrical alkenes are almost entirely unknown. Here we report for the first time a systematic experimental exploration of the stabilisation of $\mathrm{CH}_{2} \mathrm{OO}$ and $\left(\mathrm{CH}_{3}\right)_{2} \mathrm{COO} \mathrm{Cl}$, formed from ten alkeneozone systems with a range of different sizes and structures, under atmospherically relevant conditions in the EUPHORE chamber. Experiments in the presence of excess $\mathrm{SO}_{2}$ (an $\mathrm{SCl}$ scavenger) determined total $\mathrm{SCl}$ yields from each alkene-ozone system. Comparison of primary carbonyl yields in the presence/absence of $\mathrm{SO}_{2}$ determined the stabilisation fraction of a given $\mathrm{Cl}$. The results show that the stabilisation of a given $\mathrm{Cl}$ increases as the size of the carbonyl co-product increases. This is interpreted in terms of the nascent population of $\mathrm{Cl}$ formed following decomposition of the primary ozonide (POZ) having a lower mean energy distribution when formed with a larger carbonyl co-product, as more of the energy from the POZ is taken by the carbonyl. These findings have significant implications for atmospheric modelling of alkene ozonolysis. Higher stabilisation of small $\mathrm{Cl}$ formed from large alkenes is expected to lead to lower radical yields from $\mathrm{Cl}$ decomposition, and higher $\mathrm{SCl}$ concentrations, increasing the importance of $\mathrm{SCl}$ bimolecular reactions.
\end{abstract}

\section{Introduction}

The formation of Criegee intermediates (CI) from gas phase alkene ozonolysis has received attention over the past five decades owing to their role as important non-photolytic sources of radicals $(\mathrm{OH}$, $\mathrm{HO}_{2}$ and $\mathrm{RO}_{2}$ ) to the troposphere. ${ }^{1-5}$ More recently, the potential importance of bimolecular reactions of stabilised CI (SCI) has been the subject of much research (see Vereecken et al. ${ }^{6}$ and references within). These reactions contribute significantly to the sulfuric acid budget in certain environments through oxidation of $\mathrm{SO}_{2},{ }^{7}$ and the acidity of the atmosphere through removal of organic and inorganic acids. ${ }^{8}$ Bimolecular reactions of SCI have also been implicated in the formation of aerosol from monoterpene ozonolysis $^{9}$ through dimerization, ${ }^{10,11}$ oligomerization $^{12}$ and reaction with peroxy radicals, ${ }^{13}$ contributing to new particle

\footnotetext{
${ }^{a}$ Wolfson Atmospheric Chemistry Laboratories, Department of Chemistry, University of York, UK. E-mail: mike.newland@gmail.com

${ }^{b}$ Fundación CEAM, EUPHORE Laboratories, Avda Charles R. Darwin 14. Parque Tecnológico, Valencia, Spain

${ }^{c}$ National Centre for Atmospheric Science, Wolfson Atmospheric Chemistry Laboratories, University of York, UK

$\dagger$ Electronic supplementary information (ESI) available. See DOI: 10.1039/d0cp00897d
}

formation $^{14}$ and so directly affecting cloud condensation nuclei, ${ }^{15,16}$ rainfall, and climate.

The Criegee ozonolysis reaction mechanism ${ }^{17}$ proceeds via concerted cycloaddition of the ozone molecule across the $\mathrm{C}=\mathrm{C}$ double bond to form a chemically activated primary ozonide (POZ), followed by cleavage of the $\mathrm{C}-\mathrm{C}$ bond and one of the $\mathrm{O}-\mathrm{O}$ bonds forming a carbonyl molecule and a carbonyl oxide, or 'Criegee intermediate', ${ }^{18}$ see Scheme 1 . A population of ozonolysis derived CIs in the gas-phase is formed with a broad internal energy distribution. ${ }^{19}$ A fraction of CI may be formed 'cold' (although this is not the case for all alkenes ${ }^{20,21}$ ), that is, without enough internal energy to undergo prompt decomposition, these are termed stabilised Criegee intermediates (SCI). The remainder are formed chemically activated $\left(\mathrm{CI}^{*}\right)$. These $\mathrm{CI}^{*}$ tend to undergo prompt decomposition on a timescale of nanoseconds. ${ }^{22} \mathrm{How}^{-}$ ever, they can also be collisionally deactivated to add to the SCI population. The distinction between these two routes to SCI formation has been demonstrated in laboratory experiments performed as a function of pressure. ${ }^{20,21,23-25}$ The fraction of each type of CI that is formed will depend on the initial energy distribution of the CI population. ${ }^{24}$

Unimolecular decomposition of CI yields a range of radical products, with decomposition of syn-CI (i.e. CI with an alkyl 


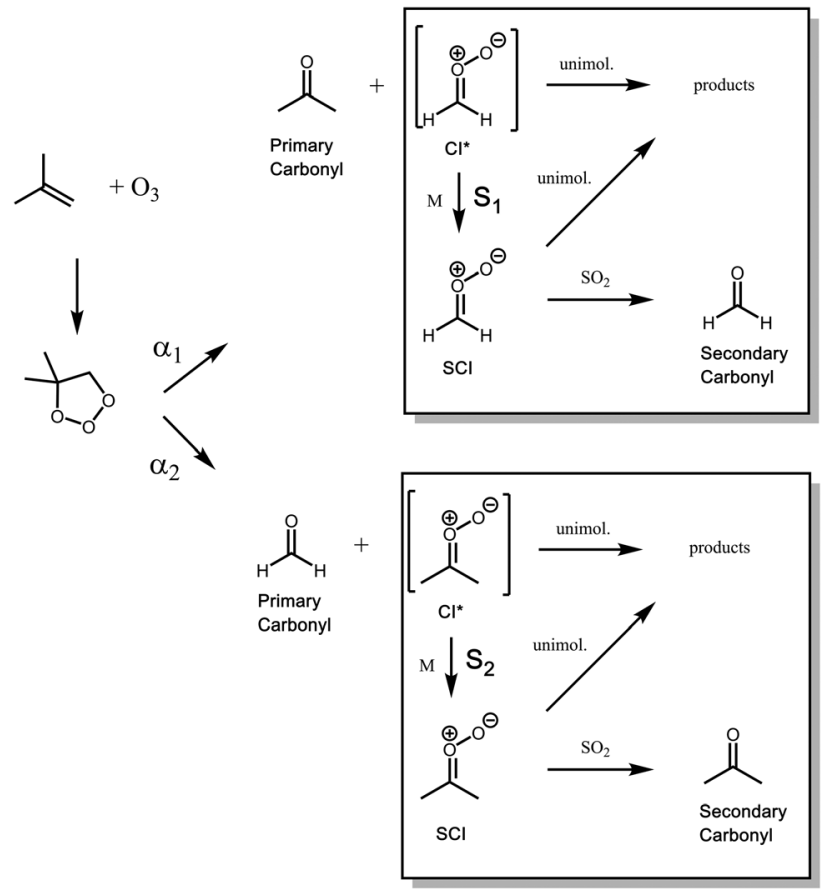

Scheme 1 Simplified mechanism for the production of $\mathrm{Cl}$ and primary and secondary carbonyl products in the ozonolysis of 2-methyl propene.

group on the same side of the terminal $\mathrm{O}$ atom of the carbonyl oxide moiety), via a vinyl hydroperoxide, producing $\mathrm{OH}$ with (near) unit yield. SCI can have sufficiently long lifetimes to undergo bimolecular reactions with $\mathrm{H}_{2} \mathrm{O}, \mathrm{RCOOH}$, and $\mathrm{SO}_{2}$, amongst other species, in the atmosphere. Hence the relative yields of CI/SCI from a particular alkene-ozone system determine the effect of that system on atmospheric composition.

Inclusion of alkene ozonolysis chemistry in regional and global chemical transport models is essential to correctly estimate radical concentrations, and the product distribution from the removal of alkenes by reaction with ozone. However, such mechanisms must firstly parameterize SCI yields for a structurally diverse range of alkenes for which no measurements exist, lumping together SCI of different structures and hence reactivities, and secondly lumping together stabilisation of different SCI. This leads to large uncertainties on the SCI yields and hence on the effect of alkene-ozone reactions on atmospheric composition.

Many laboratory studies probing the chemistry of SCI have utilised the facile photolysis of alkyl iodides to yield SCI in the presence of oxygen. ${ }^{26}$ This has proved an invaluable resource for the study of SCI chemistry. However, alkene ozonolysis is expected to be the dominant source of $\mathrm{CI}$ to the atmosphere, and certain atmospherically relevant questions, such as the fractional CI and SCI yields from alkene ozonolysis, can only be answered by probing the alkene-ozone system.

Total SCI yields have previously been measured from a number of atmospherically relevant alkene-ozone systems including short chain alkenes, ${ }^{27-31}$ isoprene, ${ }^{32-34}$ and monoterpenes. ${ }^{7,32}$ These yields are generally measured indirectly, either by the removal of an SCI scavenger $\left(e . g . \mathrm{SO}_{2}\right)$ or formation of a product from an SCI scavenging reaction (e.g. production of $\mathrm{H}_{2} \mathrm{SO}_{4}$, via the $\mathrm{SO}_{2}+$ SCI reaction). However, very little experimental information exists on the relative amounts of different SCI formed in nonsymmetrical systems. For non-symmetrical, non-cyclic, alkenes, a pair of CI and carbonyl co-products are formed (Scheme 1). The yield of each SCI depends on: (i) the yield of each CI determined by the fragmentation of the $\mathrm{POZ}(\alpha)$; (ii) the fraction of each CI that is stabilised $(S)$. The stabilisation of a given CI produced from different alkene-ozone systems might be expected to differ. For example, while the fraction of $\mathrm{CH}_{2} \mathrm{OO}$ stabilised in ethene ozonolysis has been determined to be 0.35-0.54 based on a wide range of experimental studies, the chamber studies of Nguyen $e t a l .^{34}$ suggest that the majority of $\mathrm{CH}_{2} \mathrm{OO}$ formed in isoprene ozonolysis is stabilised.

Here, we present results of a series of alkene ozonolysis experiments carried out at the European PhotoReactor facility (EUPHORE), Valencia, Spain, in which yields of chemically activated and stabilised $\mathrm{CH}_{2} \mathrm{OO}$ and $\left(\mathrm{CH}_{3}\right)_{2} \mathrm{COO}$ are determined, for the first time, for a systematic range of alkene-ozone systems under atmospherically relevant conditions. An empirical structureactivity relationship for the stabilisation of these types of Criegee intermediates, based on the size of the carbonyl co-product formed in the decomposition of the primary ozonide is also presented, with the atmospheric implications of the results discussed.

\section{Experimental}

\section{EUPHORE}

EUPHORE is a $200 \mathrm{~m}^{3}$ simulation chamber used for studying reaction mechanisms under atmospheric boundary layer conditions. The chamber is fitted with large horizontal and vertical fans to ensure rapid mixing (three minutes). Further details of the chamber setup and instrumentation are available elsewhere. ${ }^{35-37}$ Experiments comprised time-resolved measurement of the formation of carbonyl products and the loss of alkene and ozone (and in some experiments $\left.\mathrm{SO}_{2}\right)$. $\mathrm{SO}_{2}$ and $\mathrm{O}_{3}$ abundance were measured using conventional fluorescence and UV absorption monitors, respectively; alkene and oxygenated volatile organic compound abundance was determined via FTIR spectroscopy and PTR-MS. The precision of the $\mathrm{SO}_{2}$ and $\mathrm{O}_{3}$ monitors were 0.25 and 0.47 ppbv respectively (evaluated as 2 standard deviations of the measured value prior to $\mathrm{SO}_{2}$ or $\mathrm{O}_{3}$ addition). Experiments were performed in the dark (i.e., with the chamber housing closed; $j\left(\mathrm{NO}_{2}\right) \leq 10^{-6} \mathrm{~s}^{-1}$ ), at atmospheric pressure ( $c a .1000 \mathrm{mbar}$ ) and temperatures between 297 and $305 \mathrm{~K}$, on timescales of $c a$. 30-90 minutes. Chamber dilution was monitored via the first order decay of an aliquot of $\mathrm{SF}_{6}$, added prior to each experiment. Cyclohexane ( $c a .75 \mathrm{ppmv}$ ) was added at the beginning of each experiment to act as an $\mathrm{OH}$ scavenger, such that $\mathrm{SO}_{2}$ reaction with $\mathrm{OH}$ was calculated to be $\leq 1 \%$ of the total chemical $\mathrm{SO}_{2}$ removal in all experiments.

\section{Experimental approach}

Experimental procedure comprised addition of $\mathrm{SF}_{6}$ and cyclohexane, followed by $\mathrm{O}_{3}(c a .1000 \mathrm{ppbv}$ for the experiments with 
alkenes producing $\mathrm{CH}_{2} \mathrm{OO}$, which generally have reaction rates with ozone $\sim 1 \times 10^{-17} \mathrm{~cm}^{3} \mathrm{~s}^{-1}$; and $c a .500 \mathrm{ppbv}$ for the experiments with alkenes producing $\left(\mathrm{CH}_{3}\right)_{2} \mathrm{COO}$, which generally have reaction rates with ozone $\sim 1 \times 10^{-16} \mathrm{~cm}^{3} \mathrm{~s}^{-1}$ ) and $\mathrm{SO}_{2}$ if used ( $c a .2000 \mathrm{ppbv}$ ). A gap of five minutes was left prior to addition of the alkene, to allow complete mixing. The reaction was then initiated by addition of the alkene ( $\mathrm{ca} .800 \mathrm{ppbv}$ for the systems producing $\mathrm{CH}_{2} \mathrm{OO}$, and $400 \mathrm{ppbv}$ for those producing $\left.\left(\mathrm{CH}_{3}\right)_{2} \mathrm{COO}\right)$. The chamber was monitored for 30-90 minutes subsequent to the addition of the alkene depending on the rate of reaction with ozone, the rate of alkene/ozone consumption being dependent on $k$ (alkene + ozone). Roughly $50 \%$ of the $\mathrm{CH}_{2} \mathrm{OO}$ producing alkenes were consumed after 60 minutes, while $90 \%$ of the faster reacting alkenes were consumed within roughly 25 minutes. The experiments were performed under dry conditions $(\mathrm{RH}<1 \%)$. A full experiment list is given in Table S1 (ESI $\dagger$ ).

\section{Results and discussion}

\section{Total SCI yields}

Alkene ozonolysis experiments were performed in the presence of $c a .2000$ ppbv $\mathrm{SO}_{2}$, such that the overwhelming majority ( $\geq 94 \%$ ) of the SCI was scavenged and converted to a carbonyl. The total SCI yield, $\phi$, was calculated by regressing the loss of ozone $\left(\mathrm{dO}_{3}\right)$ against the loss of $\mathrm{SO}_{2}\left(\mathrm{dSO}_{2}\right)$ (eqn (E1)), both corrected for chamber dilution. In reality the experimentally determined value of $\phi$ is a minimum value, $\phi_{\min }$ since other loss channels for the SCI (e.g. decomposition) may still be having a small but non-negligible effect (Newland et al. (2015a)), accounted for in eqn (E1) by $f$.

$$
\frac{\mathrm{dSO}_{2}}{\mathrm{dO}_{3}}=\phi_{\mathrm{SCI}-\mathrm{tot}} \cdot f=\phi_{\mathrm{SCI}-\mathrm{min}}
$$

In addition to the presence of $\mathrm{SO}_{2}$ as a potential SCI reaction partner in the chamber, there is also $\mathrm{H}_{2} \mathrm{O}(<1 \% \mathrm{RH}), \mathrm{HCOOH}$ (of the order of $10 \mathrm{ppbv}$ produced in the ozonolysis reaction), and carbonyls on the order of a few hundred ppbv. For stabilised $\mathrm{CH}_{2} \mathrm{OO}$, decomposition is slow (0.1 s $\mathrm{s}^{-1}$, IUPAC) and the only other potentially significant loss process under the experimental conditions employed was bimolecular reaction with water vapour or $\mathrm{HCOOH}$. Based on the IUPAC ${ }^{38}$ recommended rate constants, $2000 \mathrm{ppbv}$ of $\mathrm{SO}_{2}$ is estimated to scavenge $>98 \%$ of $\mathrm{CH}_{2} \mathrm{OO}$ at $\mathrm{RH}=1 \%$ and $[\mathrm{HCOOH}]=10 \mathrm{ppbv}$ (typical mixing ratio present in the chamber for the experimental conditions). For $\left(\mathrm{CH}_{3}\right)_{2} \mathrm{COO}$ the only other important loss process under the experimental conditions employed was unimolecular decomposition. $2000 \mathrm{ppbv}$ of $\mathrm{SO}_{2}$ is estimated to scavenge $94 \%$ of $\left(\mathrm{CH}_{3}\right)_{2} \mathrm{COO}$ at $303 \mathrm{~K}$ based on the IUPAC (IUPAC) recommended rates of $k\left(\left(\mathrm{CH}_{3}\right)_{2} \mathrm{COO}+\mathrm{SO}_{2}\right)=4.2 \times$ $10^{-13} \exp ^{(1761 / T)} \mathrm{cm}^{3} \mathrm{~s}^{-1}$ and $k_{\mathrm{uni}}\left(\left(\mathrm{CH}_{3}\right)_{2} \mathrm{COO}\right)=1.0 \times 10^{7}$ $\exp ^{(-3020 / T)} \mathrm{s}^{-1}$. A range of other syn- and anti-CI will be formed as co-products for many of the alkenes studied here. Using syn and anti- $\mathrm{CH}_{3} \mathrm{CHOO}$ as surrogates, under the experimental conditions employed here, $88 \%$ of syn-CI will be scavenged by $2000 \mathrm{ppbv}$ $\mathrm{SO}_{2}$, and $97 \%$ of anti-CI will be scavenged. Elsamra et al. ${ }^{39}$ determined $k\left(\mathrm{CH}_{2} \mathrm{OO}+\right.$ acetone $)=3.0( \pm 1.0) \times 10^{-13} \mathrm{~cm}^{3} \mathrm{~s}^{-1}$ and $k\left(\mathrm{CH}_{2} \mathrm{OO}+\right.$ acetaldehyde $)=1.2( \pm 0.3) \times 10^{-12} \mathrm{~cm}^{3} \mathrm{~s}^{-1}$, at $298 \mathrm{~K}$. Products of the reaction are believed to be the carbonyl + acid (e.g. $\mathrm{CH}_{2} \mathrm{OO}+\mathrm{CH}_{3} \mathrm{CHO} \rightarrow \mathrm{CH}_{3} \mathrm{COOH}+\mathrm{HCHO}$ or $\mathrm{HCOOH}+$ $\mathrm{CH}_{3} \mathrm{CHO}$ ), formed via decomposition of a secondary ozonide. ${ }^{40} \mathrm{At}$ 200 ppbv of the carbonyl, this would lead to a sink for $\mathrm{CH}_{2} \mathrm{OO}$ of the order of $1-10 \mathrm{~s}^{-1},<1 \%$ in $\mathrm{SO}_{2}$ scavenger experiments. Other potential SCI sinks, such as self-reaction are negligible under our experimental setup.

Total SCI yields were calculated for ten alkene-ozone systems in this work $\left(\mathrm{C}_{2}-\mathrm{C}_{10}\right)$. Fig. 1 shows an example plot of $\Delta \mathrm{SO}_{2} v s$. $\Delta \mathrm{O}_{3}$ for an ozonolysis experiment with 2,4-dimethyl-pent-2-ene. Uncertainties are $\pm 2 \sigma$ and represent the combined systematic (estimated measurement uncertainty) and precision components. Fig. S1 (ESI $\dagger$ ) shows total SCI plots for each of the ten alkenes studied. Table 1 gives the total SCI yields corrected for additional SCI losses, i.e. $f$, (see Tables $\mathrm{S} 2$ and $\mathrm{S} 3$, ESI $\dagger$ this correction generally increased the yields by $\sim 5 \%$ ) calculated for each alkene, and values previously reported in the literature where available.

For alkenes for which total SCI yields have been measured previously, there is good agreement between the values measured here and those reported in the literature. The ethene-ozone system is the most studied, with reported SCI yields ranging from $0.35-0.54$, from a range of different techniques - see Newland et al.;1 Alam et al. ${ }^{36}$ for further references. The value of $0.43( \pm 0.02)$ derived here lies towards the lower end of this range. For propene only two values exist in the literature. The value of $0.28( \pm 0.02)$ derived here is in good agreement with the value of $0.25( \pm 0.02)$ from Hatakeyama et $a .^{28}$ from determination of $\mathrm{H}_{2} \mathrm{SO}_{4}$ production relative to ozone loss in chamber experiments, and considerably lower than the value of 0.44 from Horie and Moortgat, ${ }^{41}$ derived from analysis of carbonyl products from the propene-ozone reaction. For 2-methylpropene, Hatakeyama et $a .^{28}$ derived a value of $0.17( \pm 0.03)$, using the method described above, compared to our value of $0.21( \pm 0.04)$.

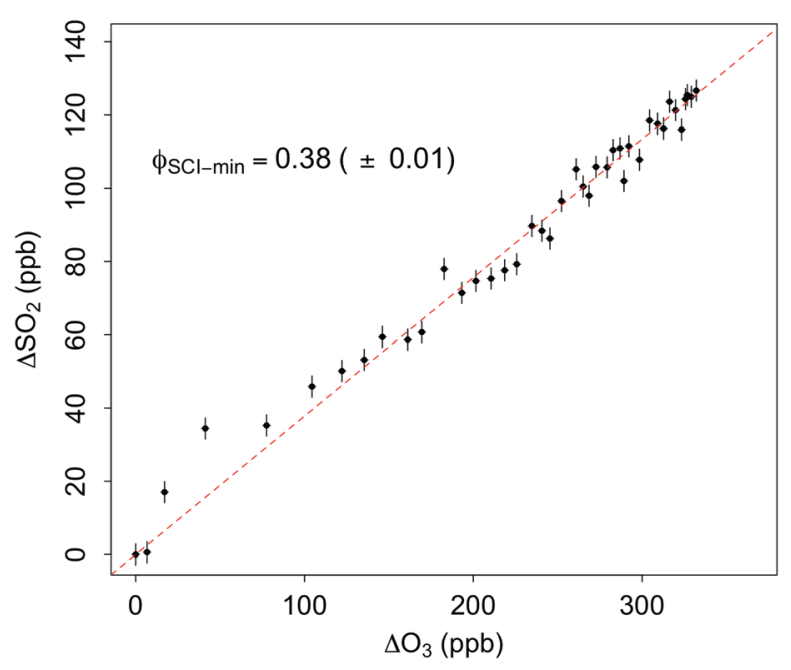

Fig. 1 Total $\mathrm{SCl}$ yield $\left(\phi_{\mathrm{SCl}-\mathrm{min}}\right)$ in 2,4-dimethyl pent-2-ene ozonolysis, derived from the removal of $\mathrm{SO}_{2}\left(\Delta \mathrm{SO}_{2}\right)$ relative to the removal of ozone $\left(\Delta \mathrm{O}_{3}\right)$ (eqn (E1)). Dashed line: linear regression of measurements. Data is not corrected for additional loss processes - see text for details. Vertical and horizontal error bars represent precision uncertainties. 
Table 1 Total $\mathrm{SCl}$ yields from the ten alkenes studied in this work. Uncertainties are $\pm 2 \sigma$, and represent the combined systematic (estimated measurement uncertainty) and precision components

\begin{tabular}{|c|c|c|c|}
\hline Alkene & SCI yield ${ }^{a}$ & Literature values & Method \\
\hline Propene $\left(\mathrm{C}_{3}\right)$ & $0.34( \pm 0.01)$ & $\begin{array}{l}0.25( \pm 0.02)^{28} \\
0.44^{41}\end{array}$ & $\begin{array}{l}\Delta \mathrm{H}_{2} \mathrm{SO}_{4} / \Delta \mathrm{O}_{3} \\
\text { Carbonyl product yields }\end{array}$ \\
\hline 2-Methyl-but-1-ene $\left(\mathrm{C}_{5}\right)$ & $0.33( \pm 0.01)$ & & \\
\hline 1-Heptene $\left(\mathrm{C}_{7}\right)$ & $0.61( \pm 0.03)$ & & \\
\hline 2-Methyl-but-2-ene $\left(\mathrm{C}_{5}\right)$ & $0.28( \pm 0.01)$ & & \\
\hline 2,3,4-Trimethyl-pent-2-ene $\left(\mathrm{C}_{8}\right)$ & $0.49( \pm 0.01)$ & & \\
\hline Myrcene $\left(\mathrm{C}_{10}\right)$ & $0.46( \pm 0.03)$ & $0.35^{42}$ & Theoretical calculations \\
\hline
\end{tabular}

Deng et $a{ }^{42}{ }^{42}$ recently reported a total SCI yield of 0.35 for the monoterpene myrcene based on theoretical calculations (82\% $\left(\mathrm{CH}_{3}\right)_{2} \mathrm{COO}, 15 \%$ large anti-SCI, 3\% large syn-SCI), compared to our measured value of 0.46 . It may be expected that our experimental yield is an underestimation due to the very fast unimolecular reaction of the large anti-SCI formed in this system (calculated by Deng et $a l^{42}$ to be $7600 \mathrm{~s}^{-1}$ ) which means that probably $<50 \%$ would be scavenged by 2000 ppbv $\mathrm{SO}_{2}$. Based on the yield of anti-SCI predicted by Deng et al. ${ }^{42}(15 \%)$, this may lead to an underestimation of the total SCI yield of $\sim 8 \%$. None of the other alkenes studied here have had total SCI yields reported previously to the authors' knowledge.

Fig. 2 shows the total SCI yields measured in this study plotted against carbon number of the parent alkene. Previous studies $^{43}$ have noted that total SCI yields do not appear to display a strong dependence on alkene size. The systems studied here suggest a weak dependence on the size of the parent alkene, with total SCI yield increasing with alkene size. Propene and 2-methylpropene have total SCI yields of $0.24-$ 0.34 , while the larger trisubstituted alkenes, 2,3,4 trimethylpent-2-ene and myrcene have yields of $0.41-0.49$, and the

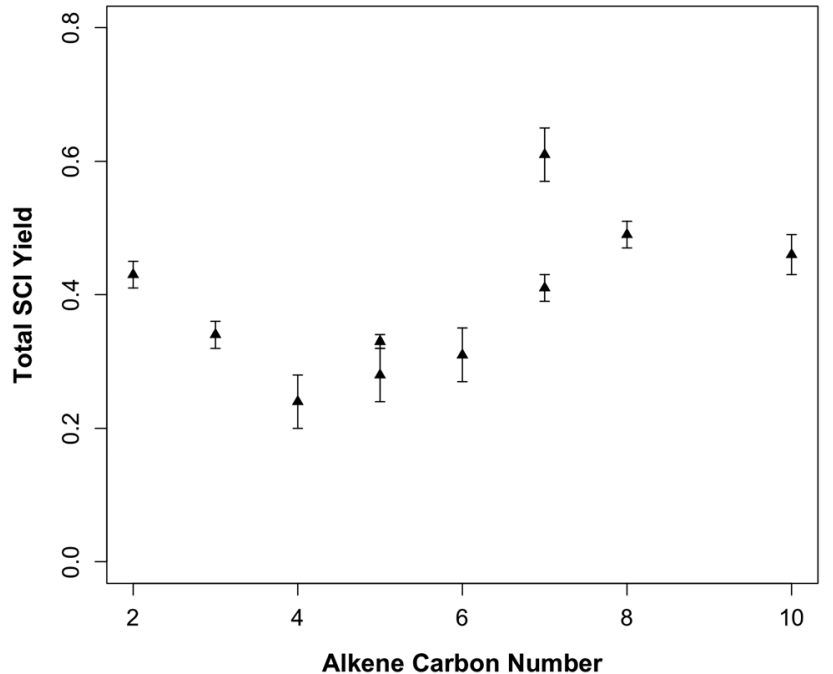

Fig. 2 Total $\mathrm{SCl}$ yields derived from ten alkene-ozone systems in this work. largest terminal alkene, 1-heptene has a yield of $0.61( \pm 0.03)$. However, as shown later the total SCI yield is the product of a number of effects and hence any simple relation to alkene size must be treated with caution.

\section{Primary carbonyl yields}

For non-symmetrical, non-cyclic, alkenes, a pair of CI and carbonyl co-products are formed in the decomposition of the POZ (Scheme 1). The sum yield of pathways $\alpha_{1}+\alpha_{2}$ (i.e. the sum yield of the two possible primary carbonyls) should be equal to one. This has been confirmed to be the case in the extensive experimental dataset of Grosjean and Grosjean ${ }^{44}$ for systems in which the smaller carbonyl is not also formed from decomposition of the larger CI. Therefore, by determining the yield of just one of the carbonyls (ideally the larger one, as it cannot be formed in CI decomposition) it is possible to determine both the primary yield of the other carbonyl, and the yield of both CI. For most CI, syn and anti conformers can also be formed because of the negligible rotation about the $\mathrm{C}=\mathrm{O}$ bond of the CI moiety (Vereecken and Francisco, 2012). However, the two CI of focus in this study, $\mathrm{CH}_{2} \mathrm{OO}$ and $\left(\mathrm{CH}_{3}\right)_{2} \mathrm{COO}$, are both symmetrical.

The relative magnitude of pathways $\alpha_{1}$ and $\alpha_{2}$ is determined by the fragmentation of the POZ. This appears to be determined predominantly by the structure around the double bond at which ozonolysis occurs. ${ }^{3,45}$ A fraction, $S$, of each of the two CI formed is stabilised, either due to being formed below the energy threshold for being chemically activated, or via collisional stabilisation. The yield of each SCI is thus given by the product of $\alpha_{i}$ and $S_{i}$ (eqn (E2); Scheme 1). The total yield of SCI from a given alkene is then the sum of the yields of the two specific SCI (eqn (E3)).

$$
\begin{gathered}
\phi_{\text {SCI-min }}=\alpha \times S \\
\phi_{\text {SCI-tot }}=\alpha_{1} \times S_{1}+\alpha_{2} \times S_{2}
\end{gathered}
$$

The primary carbonyl yields in these experiments were determined by FTIR measurement of the yield of the primary carbonyls relative to the loss of ozone (both corrected for chamber dilution) (eqn (E4)).

$$
\phi_{\text {carb- } 1^{\circ}}=\frac{\Delta \text { carbonyl }}{\Delta \mathrm{O}_{3}}
$$




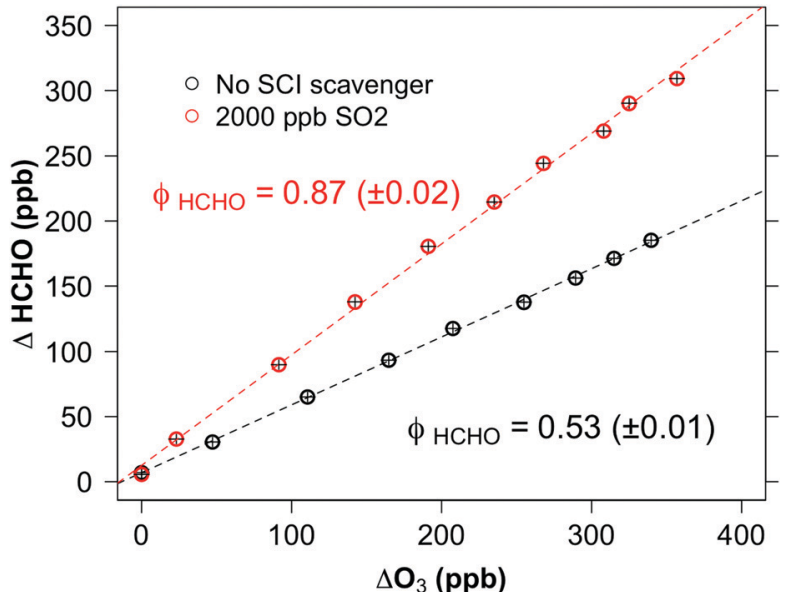

Fig. 3 Measured $\triangle \mathrm{HCHO}$ vs. $\Delta \mathrm{O}_{3}$ (both corrected for dilution) for a hept1-ene ozonolysis experiment with and without 2000 ppbv of the $\mathrm{SCl}$ scavenger $\mathrm{SO}_{2}$ present. Precision uncertainties are smaller than the presented data points.

Fig. 3 shows an example of two experiments with 1-heptene, in the presence and absence of $\mathrm{SO}_{2}$. The measured $\mathrm{HCHO}$ is plotted against ozone consumption (both corrected for chamber dilution). The $\mathrm{HCHO}$ yield of $0.52( \pm 0.01)$ in the zero $\mathrm{SO}_{2}$ experiment, represents the primary $\mathrm{HCHO}$. The $\mathrm{HCHO}$ yield is considerably higher in the $\mathrm{SO}_{2}$ scavenger experiment (0.85 $( \pm 0.03))$, because it is the sum of primary HCHO and secondary $\mathrm{HCHO}$ formed from the reaction of stabilised $\mathrm{CH}_{2} \mathrm{OO}$ with $\mathrm{SO}_{2}$ (reaction (R1)).

$$
\mathrm{CH}_{2} \mathrm{OO}+\mathrm{SO}_{2} \rightarrow \mathrm{HCHO}+\mathrm{SO}_{3}
$$

Table 2 shows the primary carbonyl yields determined for each alkene ozonolysis system studied. $\alpha_{1}$ is the pathway that leads to the $\mathrm{CI}$ being studied here, i.e. $\mathrm{CH}_{2} \mathrm{OO}$ or $\left(\mathrm{CH}_{3}\right)_{2} \mathrm{COO}$. Fig. S2 (ESI $\dagger$ ) shows plots of the primary carbonyl yields for all experiments.

For alkenes in which $\mathrm{HCHO}$ or acetone are expected to be formed in the decomposition of the larger CI, $\alpha_{1}$ was determined based on the measured yield of the larger carbonyl. HCHO is expected to be a decomposition product of any CI with a methyl group syn or anti to the carbonyl oxide moiety. ${ }^{46}$ For syn-CI this comes via decomposition of a $\beta$-oxo-alkoxy radical formed via the vinyl-hydroperoxide mechanism; for anti-CI the methyl radical is formed in decomposition of a bis-oxy radical, formed via 1,3 ring closure of the $\mathrm{CI}$, leading to $\mathrm{CH}_{3} \mathrm{O}_{2}$ and ultimately to $\mathrm{HCHO}$. For longer alkyl chains, $\mathrm{HCHO}$ is not expected to be formed. For short chain terminal alkenes this is consistent with the extensive database of ozonolysis experiments by Grosjean and Grosjean ${ }^{44}$ (and references therein). These show total primary carbonyl yields of unity for straight chain terminal alkenes with the exception of propene (that forms $\mathrm{CH}_{3} \mathrm{CHOO}$ ), for which the sum carbonyl yield is well in excess of 1 (1.30). Any alkene that produces $\left(\mathrm{CH}_{3}\right)_{2} \mathrm{COO}$ will also have a large secondary $\mathrm{HCHO}$ yield from decomposition of this CI.

\section{CI stabilisation}

The stabilisation, $S$, of a given $\mathrm{CI}$ is calculated as the ratio of the yield, $\phi$, of the SCI to the yield of the CI (eqn (E5)). $\phi_{\mathrm{CI}}$ is calculated as described above, based on the primary carbonyl yields in experiments with no SCI scavenger. $\phi_{\mathrm{SCI}}$ for a specific CI is determined from the difference between the carbonyl yields in experiments with and without an SCI scavenger. The calculated stabilisation of $\mathrm{CH}_{2} \mathrm{OO}$ and $\left(\mathrm{CH}_{3}\right)_{2} \mathrm{COO}$ in the alkene systems studied here are given in Table 3.

$$
S=\frac{\phi_{\mathrm{SCI}}}{\phi_{\mathrm{CI}}}=\frac{\phi_{\mathrm{SCI}}}{\alpha}=\frac{\phi_{\mathrm{carb} 2^{\circ}}-\phi_{\mathrm{carb} 1^{\circ}}}{\phi_{\mathrm{CI}}}
$$

where carb $2^{\circ}$ is the secondary yield of the carbonyl, i.e. from $\mathrm{SCI}+\mathrm{SO}_{2}$, and carb $1^{\circ}$ is the primary yield of the carbonyl. For systems in which the carbonyl of interest (i.e. HCHO/acetone) could also be formed from decomposition of the larger CI, $S$ is calculated by rearranging eqn (E3)-(E6).

$$
S_{1}=\frac{\phi_{\text {SCI-tot }}-\left(\alpha_{2} \times S_{2}\right)}{\alpha_{1}}
$$

Table 2 Carbonyl yields and POZ decomposition branching ratios $(\alpha)$ from the ten alkenes studied here. The $\alpha_{2}$ pathway leads to the $\mathrm{Cl}$ being studied

\begin{tabular}{|c|c|c|c|c|c|c|}
\hline Alkene & \multicolumn{2}{|l|}{ Zero $\mathrm{SO}_{2}$} & \multicolumn{2}{|l|}{ High $\mathrm{SO}_{2}$} & $\alpha_{1}$ & $\alpha_{2}$ \\
\hline \multicolumn{7}{|l|}{ Carb1 $=$ HCHO } \\
\hline Propene & $0.61( \pm 0.04)$ & $0.38( \pm 0.06)$ & $0.84( \pm 0.02)$ & $0.62( \pm 0.02)$ & 0.62 & 0.38 \\
\hline 2-Methyl-but-1-ene & $0.93( \pm 0.01)$ & $0.40( \pm 0.01)$ & $1.05( \pm 0.03)$ & $0.50( \pm 0.01)$ & 0.60 & 0.40 \\
\hline 1-Heptene & $0.53( \pm 0.01)$ & $0.42( \pm 0.01)$ & $0.84( \pm 0.03)$ & $0.80( \pm 0.12)$ & 0.53 & 0.47 \\
\hline 2-Methyl-but-2-ene & $0.34( \pm 0.01)$ & $0.80( \pm 0.07)$ & $0.44( \pm 0.02)$ & $0.69( \pm 0.12)$ & 0.34 & 0.66 \\
\hline 2,3-Dimethyl-but-2-ene & $1.05( \pm 0.01)$ & - & $1.38( \pm 0.05)$ & N.A. & $1.00^{b}$ & - \\
\hline 2,4-Dimethylpent-2-ene & $0.22( \pm 0.01)$ & $1.04( \pm 0.03)$ & $0.50( \pm 0.02)$ & $0.94( \pm 0.05)$ & 0.22 & 0.78 \\
\hline 2,3,4-Trimethylpent-2-ene & $0.44( \pm 0.01)$ & $0.78( \pm 0.01)$ & $0.59( \pm 0.07)$ & $0.72( \pm 0.08)$ & 0.22 & 0.78 \\
\hline Myrcene & $0.22( \pm 0.01)$ & - & $0.61( \pm 0.03)$ & - & 0.22 & 0.78 \\
\hline
\end{tabular}
here, i.e. $\mathrm{CH}_{2} \mathrm{OO}$ or $\left(\mathrm{CH}_{3}\right)_{2} \mathrm{COO}$. Carbonyl products were measured by FTIR. Uncertainties are $\pm 2 \sigma$ and represent the combined systematic (estimated measurement uncertainty) and precision components

${ }^{a}$ Carb2 $=$ the carbonyl formed from POZ decomposition that is not HCHO/acetone. ${ }^{b}$ Assumed to be 1 by definition. 
Table 3 Stabilisation of $\mathrm{CH}_{2} \mathrm{OO} /\left(\mathrm{CH}_{3}\right)_{2} \mathrm{COO}$ formed in the ten alkene systems studied. Calculated using either eqn (E5) and (E6) - see text for details. For ethene and 2,3-dimethyl-but-2-ene stabilisation of the $\mathrm{Cl}$ is equal to the total $\mathrm{SCl}$ yield shown in Table 2

\begin{tabular}{lcc}
\hline Alkene & Stab. $(S)$ & Method \\
\hline $\mathrm{CH}_{2} \mathrm{OO}$ & & \\
Ethene & $0.43( \pm 0.02)$ & $a$ \\
Propene & $0.60( \pm 0.10)$ & $b$ \\
2-Methylpropene & $0.61( \pm 0.12)$ & $(\mathrm{E} 6)$ \\
2-Methyl-but-1-ene & $0.56( \pm 0.10)$ & (E6) \\
Hept-1-ene & $0.73( \pm 0.08)$ & (E5) \\
& & \\
$\left(\mathrm{CH}_{3}\right)_{2} \mathrm{COO}$ & $0.10( \pm 0.04)$ & $(\mathrm{E} 5)$ \\
2-Methylpropene & $0.16( \pm 0.04)$ & $(\mathrm{E} 5)$ \\
2-Methyl-but-2-ene & $0.31( \pm 0.03)$ & $(\mathrm{E} 5)$ \\
2,3-Dimethyl-but-2-ene & $0.38( \pm 0.04)$ & $b$ \\
2,4-Dimethylpent-2-ene & $0.53( \pm 0.04)$ & (E5) \\
2,3,4-Trimethylpent-2-ene & $0.53( \pm 0.04)$ & \\
Myrcene & & \\
${ }^{a}$ Symmetrical, therefore total SCI yield (Table 2). & ${ }^{b}$ From model fit to \\
data (Fig. S2, ESI). & &
\end{tabular}

where $S_{1}$ is the stabilisation of $\mathrm{CH}_{2} \mathrm{OO}$ or $\left(\mathrm{CH}_{3}\right)_{2} \mathrm{COO}, S_{2}$ is the stabilisation of the other CI, calculated using eqn (E5).

\section{Discussion}

Fig. 4 shows the observed relationship between the stabilisation of the $\mathrm{CI}$ and the carbon number of the carbonyl coproduct formed in $\mathrm{POZ}$ decomposition. There is a clear increase in stabilisation of both $\mathrm{CH}_{2} \mathrm{OO}$ and $\left(\mathrm{CH}_{3}\right)_{2} \mathrm{COO}$ with increasing carbon number of the carbonyl co-product. This can be considered in terms of the distribution of the total energy available from decomposition of the POZ. If it is assumed that the total energy liberated in decomposition of the $\mathrm{POZ}$ is independent of the size of the alkene, ${ }^{19}$ and that the available energy has time to become distributed equally between the non-hydrogen atoms (i.e. $\mathrm{C}$ and $\mathrm{O}$ ), then as the size of the carbonyl co-product increases relative to the CI, so the proportion of the available energy that is taken by the CI will decrease. This would be expected to yield a CI population with a lower mean energy distribution, both increasing the yield of CI that are 'born cold', and also increasing the amount of $\mathrm{CI}$ that will be collisionally stabilised (Fig. 5). While theoretical work has shown that the energy distribution between $\mathrm{CI}$ and carbonyl fragments in $\mathrm{POZ}$ decomposition may be non-statistical, ${ }^{47,48}$ it might still be expected that the general relationship will hold.

Based on the discussion above, the data presented in Fig. 4 can be fitted by the general relationship given in eqn (E7).

$$
S=1-\left(A_{\mathrm{CI}} / A_{\text {tot }}\right) \times F
$$

where $A_{\mathrm{CI}}$ is the number of non-hydrogen atoms (i.e. $\mathrm{C}$ and $\mathrm{O}$ ) in the CI; $A_{\text {tot }}$ is the total number of non-hydrogen atoms in the $\mathrm{POZ}$; and $F$ is a factor determined from the total SCI yield of the symmetrical alkene (i.e. ethene for $\mathrm{CH}_{2} \mathrm{OO}$ and 2,3-dimethylbut-2-ene for $\left.\left(\mathrm{CH}_{3}\right)_{2} \mathrm{COO}\right)$.

The relationship is plotted in Fig. 4 (red dashed line) for a SCI yield from ethene of 0.43 (lower limit of 0.39 , upper limit

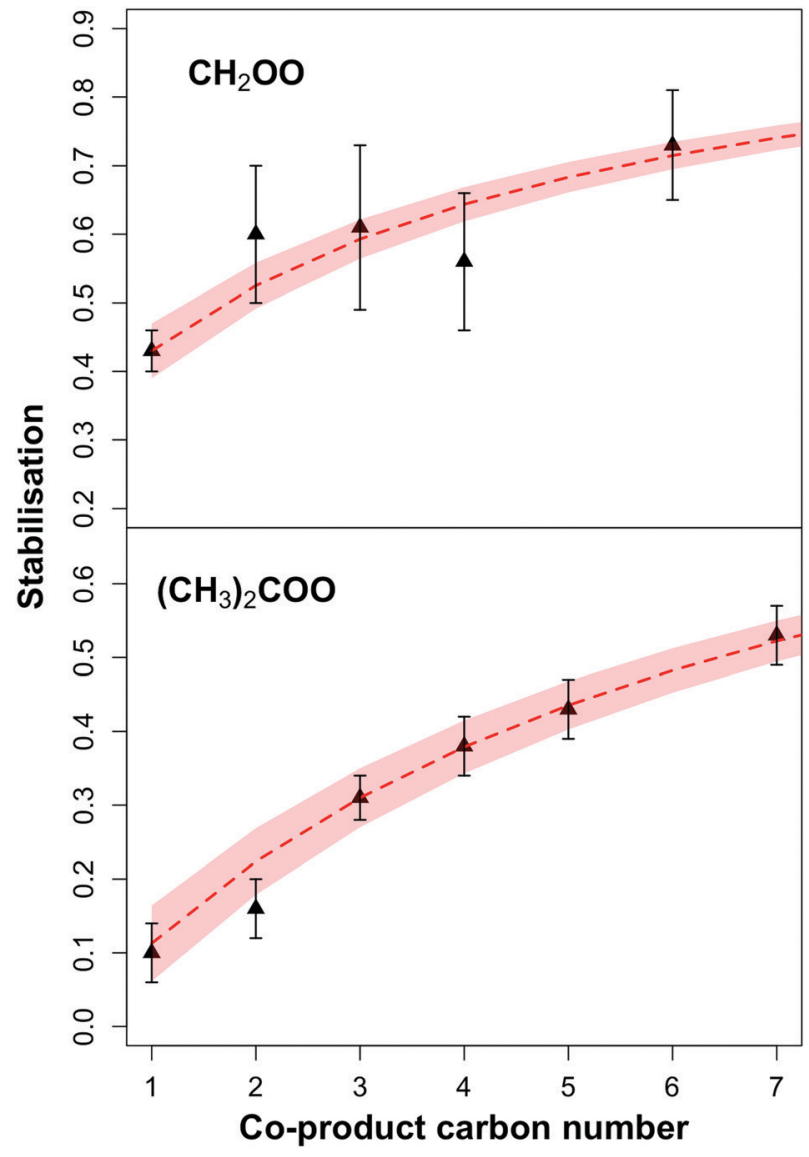

Fig. 4 Black triangles: variation of the stabilisation (S), of $\mathrm{CH}_{2} \mathrm{OO}$ and $\left(\mathrm{CH}_{3}\right)_{2} \mathrm{COO}$ with size of carbonyl co-product determined from experiment. Red dashed line: modelled stabilisation using eqn (E7), assumes $\mathrm{SCl}$ yields of $0.43( \pm 0.04)$ and $0.31( \pm 0.04)$ for ethene $\left(\mathrm{CH}_{2} \mathrm{OO}\right)$ and 2,3-dimethyl-but-2-ene $\left(\left(\mathrm{CH}_{3}\right)_{2} \mathrm{COO}\right)$ respectively.

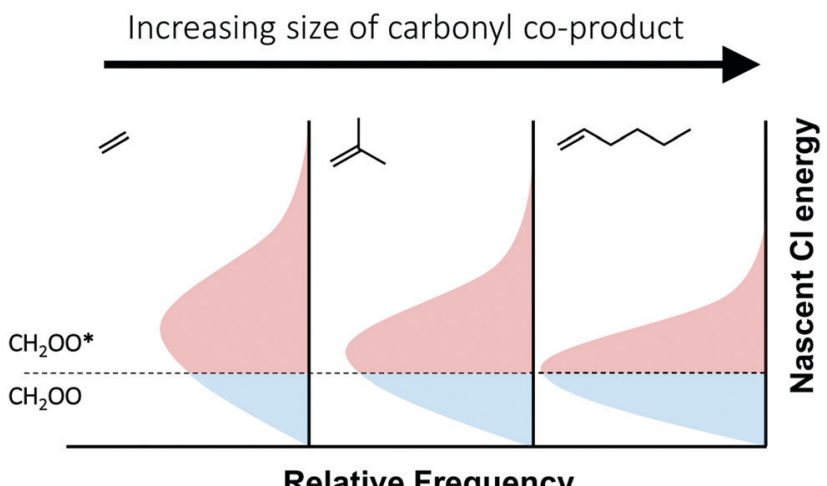

Fig. 5 Schematic showing the effect of increasing the size of the carbonyl co-product on the nascent mean energy distribution of a population of $\mathrm{Cl}$ formed following POZ decomposition. As the mean energy decreases, the fraction of $\mathrm{SCl}$ increases.

of 0.43), and from 2,3-dimethyl-but-2-ene of $0.31(0.27-0.35)$. It is seen that the prescribed relationship fits the observed data well. While there are certainly likely to be additional factors influencing the stabilisation of CI, such as specific substituents 
and more complex structures, this work shows that the number of carbons in the system is a strong determinant of CI stabilisation, particularly for systems with similar structures.

For CI stabilisation from a given alkene, there is expected to be three important effects: (i) collisional stabilisation of the POZ, which will then decompose to yield exclusively stabilised CI - this has been predicted to be significant (65\%) for the $\mathrm{C}_{15}$ sesquiterpene $\beta$-caryophyllene ${ }^{49}$ but to be insignificant for smaller $\left(<\mathrm{C}_{15}\right)$ alkenes; $^{50}$ (ii) an increased stabilisation of a given CI with increasing parent alkene size, as shown herein; and (iii) an increased stabilisation of larger CI, which have longer lifetimes (due to distributing the initial energy from the POZ decomposition among a greater number of degrees of freedom) allowing greater collisional stabilisation. ${ }^{20}$ This effect is particularly noticeable for 1-heptene in this dataset, with stabilisation of the larger CI, hexanal oxide being high $(\sim 50 \%)$.

Using the relationships shown here it is possible to calculate the stabilisation of a given CI produced from an alkene that also produces either $\mathrm{CH}_{2} \mathrm{OO}$ or $\left(\mathrm{CH}_{3}\right)_{2} \mathrm{COO}$ if the total SCI yield and the POZ decomposition branching ratio $(\alpha)$ are known. However, there are still relatively few alkenes for which total SCI yields have been measured. Further useful information to inform structure activity relationships used in atmospheric models would cover: (i) the dependence of $\alpha$ on alkene structure; (ii) trends in the total SCI yields from symmetrical alkenes of increasing size and complexity, to provide values on which to pin the relationships observed herein; (iii) the effect of the size of the CI itself on stabilisation. In addition, information on the relative yields and stabilisation of $(E) /(Z)$ CI is required to fully represent the impact of alkene ozonolysis on atmospheric composition. In addition to further experimental studies, a detailed theoretical study would provide strong corroborating evidence both for the relationship derived in this work, and the further work suggested here.

\section{Atmospheric implications}

This work suggests that small CI produced from large alkenes found in the atmosphere, e.g. isoprene, monoterpenes, sesquiterpenes, etc., will predominantly be formed stabilised. For $\mathrm{CH}_{2} \mathrm{OO}$, the SCI of which reacts almost entirely with water vapour in the boundary layer, this will result in a high yield of the products of the $\mathrm{CH}_{2} \mathrm{OO}+\mathrm{H}_{2} \mathrm{O} /\left(\mathrm{H}_{2} \mathrm{O}\right)_{2}$ reaction, and low radical $\left(\mathrm{OH}\right.$ and $\mathrm{HO}_{2}$ ) yields (although it has been suggested that radical yields from $\mathrm{CH}_{2} \mathrm{OO}$ decomposition are low anyway ${ }^{51,52}$ ). This finding is particularly important for isoprene, the most abundantly emitted alkene to the atmosphere. ${ }^{53}$ Nguyen et al. ${ }^{34}$ suggested that the total SCI yield $(\sim 0.6)^{32-34}$ measured from isoprene ozonolysis is almost entirely stabilised $\mathrm{CH}_{2} \mathrm{OO}$ (rather than the $\mathrm{C}_{4}$-CI). The main products of the reaction of $\mathrm{CH}_{2} \mathrm{OO}$ with water vapour are thought to be hydroxy-methylhydroperoxide (HMHP) and formic acid $(\mathrm{HCOOH}),{ }^{54}$ but recent flow tube experiments ${ }^{55}$ suggest a roughly equal split between HMHP and formaldehyde (HCHO) from the $\mathrm{CH}_{2} \mathrm{OO}+\left(\mathrm{H}_{2} \mathrm{O}\right)_{2}$ reaction, with direct $\mathrm{HCOOH}$ formation $<5 \%$. The dominant fate of HMHP in the atmosphere is unclear, with a relatively long lifetime against reaction with $\mathrm{OH}$ of about 1 day. ${ }^{56} \mathrm{OH}$ reaction was shown to yield $\mathrm{HCOOH}$ and $\mathrm{HCHO}$ in a ratio of $0.88 .{ }^{56}$ For $\left(\mathrm{CH}_{3}\right)_{2} \mathrm{COO}$, and other small syn-CI, for which reaction with water vapour is a negligible sink under boundary layer conditions, ${ }^{55}$ a higher stabilisation will lead to an increased atmospheric concentration of these SCI. Under typical boundary layer conditions these SCI will participate in bimolecular reactions (e.g. with $\mathrm{SO}_{2}$ and organic acids), contribute to aerosol formation, or undergo unimolecular decomposition.

\section{Conclusions}

Ozonolysis experiments were performed at the EUPHORE atmospheric simulation chamber on a range of alkenes that produce either the $\mathrm{CH}_{2} \mathrm{OO}$ or $\left(\mathrm{CH}_{3}\right)_{2} \mathrm{COO}$ Criegee intermediates. Total stabilised Criegee intermediate (SCI) yields were determined from the temporal decay of the SCI scavenger $\mathrm{SO}_{2}$. Speciated CI yields were determined based on FTIR measurements of primary carbonyl products. Speciated SCI yields were determined from comparison of carbonyl yields in the presence/absence of the SCI scavenger $\mathrm{SO}_{2}$. From this information, the stabilisation of $\mathrm{CH}_{2} \mathrm{OO}$ and $\left(\mathrm{CH}_{3}\right)_{2} \mathrm{COO}$ from each alkene was determined. The stabilisation is shown to increase with increasing carbon number of the carbonyl co-product formed in the decomposition of the primary ozonide. Stabilisation of $\mathrm{CH}_{2} \mathrm{OO}$ increases from a minimum of $\sim 0.4$ from ethene, to 0.71 from 1-heptene. Stabilisation of $\left(\mathrm{CH}_{3}\right)_{2} \mathrm{COO}$ increases from $<0.1$ from isobutene, to 0.50 from the monoterpene myrcene. An empirical relationship based on the energy distribution through the molecule on dissociation of the POZ fits the observed data well. This trend has implications for predicted tropospheric concentrations of SCI, with current models generally using SCI yields based on the total yield from the relevant symmetrical alkene-ozone system. From this work it is shown that stabilisation of small CI from many atmospherically relevant alkenes, such as isoprene and monoterpenes, is likely to be considerably higher than currently predicted. This would increase the importance of bimolecular reactions, and reduce radical yields from CI decomposition.

\section{Data availability}

Experimental data will be available in the Eurochamp database, www.eurochamp.org, from the H2020 EUROCHAMP2020 project, GA no. 730997.

\section{Conflicts of interest}

There are no conflicts to declare.

\section{Acknowledgements}

We would like to thank Luc Vereecken for very helpful discussions. The assistance of the EUPHORE staff is gratefully acknowledged. This work has received funding from the European Union's Horizon 2020 research and innovation programme through the EUROCHAMP-2020 Infrastructure Activity under grant agreement No. 730997, by means of its Transnational Activities, 
and Fundacion CEAM and the Generalitat Valenciana for the IMAGINA-Prometeo project (PROMETEO2019/110). Fundación CEAM is partly supported by Generalitat Valenciana. Mike Newland and Andrew Rickard also acknowledge support from the Mechanisms for Atmospheric chemistry: GeneratioN, Interpretation and FidelitY - MAGNIFY project, funded by the UK Natural Environment Research Council (NERC, via grant NE/M013448/1). Beth Nelson acknowledges the NERC SPHERES Doctoral Training Partnership (DTP) for her studentship.

\section{Notes and references}

1 H. Niki, P. D. Maker, C. M. Savage, L. P. Breitenbach and M. D. Hurley, J. Phys. Chem., 1987, 91, 941-946.

2 S. E. Paulson and J. J. Orlando, Geophys. Res. Lett., 1996, 23, 3727-3730.

3 A. R. Rickard, D. Johnson, C. D. McGill and G. Marston, J. Phys. Chem. A, 1999, 103, 7656-7664.

4 G. Salisbury, A. R. Rickard, P. S. Monks, B. J. Allan, S. J. B. Bauguitte, S. A. Penkett, N. Carslaw, A. C. Lewis, D. J. Creasey, D. E. Heard, P. J. Jacobs and J. D. Lee, J. Geophys. Res.: Atmos., 2001, 106, 12669-12687.

5 D. E. Heard, L. J. Carpenter, D. J. Creasey, J. R. Hopkins, J. D. Lee, A. C. Lewis, M. J. Pilling, P. W. Seakins, N. Carslaw and K. M. Emmerson, Geophys. Res. Lett., 2004, 31, L18112.

6 L. Vereecken, A. Novelli and D. Taraborrelli, Phys. Chem. Chem. Phys., 2017, 19, 31599-31612.

7 M. J. Newland, A. R. Rickard, T. Sherwen, M. J. Evans, L. Vereecken, A. Muñoz, M. Ródenas and W. J. Bloss, Atmos. Chem. Phys., 2018, 18, 6095-6120.

8 O. Welz, A. J. Eskola, L. Sheps, B. Rotavera, J. D. Savee, A. M. Scheer, D. L. Osborn, D. Lowe, A. Murray Booth, P. Xiao, M. Anwar, H. Kahn, C. J. Percival, D. E. Shallcross and C. A. Taatjes, Angew. Chem., Int. Ed., 2014, 18, 4547-4550.

9 F. A. Mackenzie-Rae, H. J. Wallis, A. R. Rickard, K. L. Pereira, S. M. Saunders, X. Wang and J. F. Hamilton, Atmos. Chem. Phys., 2018, 18, 4673-4693.

10 K. Kristensen, T. Cui, H. Zhang, A. Gold, M. Glasius and J. D. Surratt, Atmos. Chem. Phys., 2014, 14, 4201-4218.

11 X. Zhang, R. C. McVay, D. D. Huang, N. F. Dalleska, B. Aumont, R. C. Flagan and J. H. Seinfeld, Proc. Natl. Acad. Sci. U. S. A., 2015, 46, 14168-14173.

12 Y. Sakamoto, S. Inomata and J. Hirokawa, J. Phys. Chem. A, 2013, 117, 12912-12921.

13 Y. Zhao, L. M. Wingen, V. Perraud, J. Greaves and B. J. FinlaysonPitts, Phys. Chem. Chem. Phys., 2015, 17, 12500-12514.

14 M. Ehn, E. Kleist, H. Junninen, T. Petaja, G. Lonn, S. Schobesberger, M. Dal Maso, A. Trimborn, M. Kulmala, D. R. Worsnop, A. Wahner, J. Wildt and T. F. Mentel, Atmos. Chem. Phys., 2012, 12, 5113-5127.

15 J. R. Pierce, M. J. Evans, C. E. Scott, S. D. D’Andrea, D. K. Farmer, E. Swietlicki and D. V. Spracklen, Atmos. Chem. Phys., 2013, 13, 3163-3176.

16 T. Jokinen, T. Berndt, R. Makkonen, V. M. Kerminen, H. Junninen, P. Paasonen, F. Stratmann, H. Herrmann,
A. B. Guenther, D. R. Worsnop, M. Kulmala, M. Ehn and M. Sipila, Proc. Natl. Acad. Sci. U. S. A., 2015, 23, 7123-7128. 17 R. Criegee and G. Wenner, Liebigs Ann. Chem., 1949, 564, 9-15. 18 D. Johnson and G. Marston, Chem. Soc. Rev., 2008, 37, 699-716. 19 L. Vereecken and J. S. Francisco, Chem. Soc. Rev., 2012, 41, 6259-6293.

20 G. T. Drozd and N. M. Donahue, J. Phys. Chem. A, 2011, 115, 4381-4387.

21 M. Campos-Pineda and J. Zhang, Chem. Phys. Lett., 2017, 683, 647-652.

22 G. T. Drozd, T. Kurtén, N. M. Donahue and M. I. Lester, J. Phys. Chem. A, 2017, 121, 6036-6045.

23 S. Hatakeyama and H. Akimoto, Res. Chem. Intermed., 1994, 20, 503-524.

24 G. T. Drozd, J. Kroll and N. M. Donahue, J. Phys. Chem. A, 2011, 115, 161-166.

25 J. P. Hakala and N. M. Donahue, J. Phys. Chem. A, 2016, 14, 2173-2178.

26 O. Welz, J. D. Savee, D. L. Osborn, S. S. Vasu, C. J. Percival, D. E. Shallcross and C. A. Taatjes, Science, 2012, 335, 204-207.

27 H. Niki, P. D. Maker, C. M. Savage and L. P. Breitenbach, Chem. Phys. Lett., 1977, 46, 327-330.

28 S. Hatakeyama, H. Kobayashi and H. Akimoto, J. Phys. Chem., 1984, 88, 4736-4739.

29 T. Berndt, T. Jokinen, R. L. Mauldin III, T. Petaja, H. Herrmann, H. Junninen, P. Paasonen, D. R. Worsnop and M. Sipila, J. Phys. Chem. Lett., 2012, 3, 2892.

30 T. Berndt, T. Jokinen, M. Sipilä, R. L. Mauldin, H. Herrmann, F. Stratmann, H. Junninen and M. Kulmala, Atoms. Environ., 2014, 89, 603.

31 M. J. Newland, A. R. Rickard, M. S. Alam, L. Vereecken, A. Muñoz, M. Ródenas and W. J. Bloss, Phys. Chem. Chem. Phys., 2015, 17, 4076-4088.

32 M. Sipila, T. Jokinen, T. Berndt, S. Richters, R. Makkonen, N. M. Donahue, R. L. Mauldin III, T. Kurtén, P. Paasonen, N. Sarnela, M. Ehn, H. Junninen, M. P. Rissanen, J. Thornton, F. Stratmann, H. Herrmann, D. R. Worsnop, M. Kulmala, V. M. Kerminen and T. Petäjä, Atmos. Chem. Phys., 2014, 14, 12143-12153.

33 M. J. Newland, A. R. Rickard, L. Vereecken, A. Muñoz, M. Ródenas and W. J. Bloss, Atmos. Chem. Phys., 2015, 15, 9521-9536.

34 T. B. Nguyen, G. S. Tyndall, J. D. Crounse, A. P. Teng, K. H. Bates, R. H. Schwantes, M. M. Coggon, L. Zhang, P. Feiner, D. O. Milller, K. M. Skog, J. C. Rivera-Rios, M. Dorris, K. F. Olson, A. Koss, R. J. B. Wild, S. Stephen, A. H. Goldstein, J. A. de Gouw, W. H. Brune, F. N. Keutsch, J. H. Seinfeld and P. O. Wennberg, Phys. Chem. Chem. Phys., 2016, 18, 10241-10254.

35 K. H. Becker, EUPHORE: Final Report to the European Commission, Contract EV5V-CT92-0059, Bergische Universität Wuppertal, Germany, 1996.

36 M. S. Alam, M. Camredon, A. R. Rickard, T. Carr, K. P. Wyche, K. E. Hornsby, P. S. Monks and W. J. Bloss, Phys. Chem. Chem. Phys., 2011, 13, 11002-11015.

37 A. Muñoz, E. Borrás, M. Ródenas, T. Vera and H. A. Pedersen, Environ. Sci. Technol., 2018, 52, 9136-9144. 
38 IUPAC Task Group on Atmospheric Chemical Kinetic Data Evaluation, http://iupac.pole-ether.fr.

39 R. M. I. Elsamra, A. Jalan, Z. J. Buras, J. E. Middaugh and W. H. Green, Int. J. Chem. Kinet., 2016, 48, 474-488.

40 A. Jalan, J. W. Allen and W. H. Green, Phys. Chem. Chem. Phys., 2013, 15, 16841-16852.

41 O. Horie and G. K. Moortgat, Atmos. Environ., Part A, 1991, 24, 1881-1896.

42 P. Deng, L. Wang and L. Wang, J. Phys. Chem. A, 2018, 22, 3013-3020.

43 M. E. Jenkin, S. M. Saunders and M. J. Pilling, Atmos. Environ., 1997, 31, 81-104.

44 E. Grosjean and D. Grosjean, Environ. Sci. Technol., 1997, 31, 2421-2427.

45 M. E. Jenkin, R. Valorso, B. Aumont, M. J. Newland and A. R. Rickard, Atmos. Chem. Phys., 2020, in preparation.

46 E. C. Tuazon, S. M. Aschmann, J. Arey and R. Atkinson, Environ. Sci. Technol., 1997, 31, 3004-3009.

47 G. Vayner, S. V. Addepalli, K. Song and W. L. Hase, J. Chem. Phys., 2006, 125, 014317.

48 M. Pfeifle, Y.-T. Ma, A. W. Jasper, L. B. Harding, W. L. Hase and S. J. Klippenstein, J. Chem. Phys., 2018, 148, 174306.
49 T. L. Nguyen, R. Winterhalter, G. Moortgat, B. Kanawati, J. Peeters and L. Vereecken, Phys. Chem. Chem. Phys., 2009, 11, 4173-4183.

50 N. M. Donahue, G. T. Drozd, S. A. Epstein, A. A. Presto and J. H. Kroll, Phys. Chem. Chem. Phys., 2011, 13, 10848-10857.

51 T. L. Nguyen, H. Lee, D. A. Matthews, M. C. McCarthy and J. F. Stanton, J. Phys. Chem. A, 2015, 119, 5524-5533.

52 D. Stone, K. Au, S. Sime, D. J. Medeiros, M. Blitz, P. W. Seakins, Z. Decker and L. Sheps, Phys. Chem. Chem. Phys., 2018, 20, 24940-24954.

53 K. Sindelarova, C. Granier, I. Bouarar, A. Guenther, S. Tilmes, T. Stavrakou, J.-F. Müller, U. Kuhn, P. Stefani and W. Knorr, Atmos. Chem. Phys., 2014, 14, 9317-9341.

54 P. Neeb, F. Sauer, O. Horie and G. K. Moortgat, Atmos. Environ., 1997, 31, 1417-1423.

55 L. Sheps, B. Rotavera, A. J. Eskola, D. L. Osborn, C. A. Taatjes, K. Au, D. E. Shallcross, M. A. H. Khan and C. J. Percival, Phys. Chem. Chem. Phys., 2017, 19, 21970-21979.

56 H. M. Allen, J. D. Crounse, K. H. Bates, A. P. Teng, M. P. Krawiec-Thayer, J. C. Rivera-Rios, F. N. Keutsch, J. M. St. Clair, T. F. Hanisco, K. H. Møller, H. G. Kjaergaard and P. O. Wennberg, J. Phys. Chem. A, 2018, 122, 6292-6302. 